\title{
Tópicos Educacionais
}

\section{ISSN: 2448-0215 (VERSÃO ON-LINE)}

\author{
TERCERA ARTICULACIÓN DEL TIEMPO MÍTICO Y LA FÁBULA \\ ADOLESCENTE \\ THIRD ARTICULATION OF THE MYTHICAL TIME AND THE \\ ADOLESCENT FABLE
}

\begin{abstract}
Xan Eguía ${ }^{1}$
Resumen: En este artículo se define la percepción del tiempo mítico como referencia a los mitos personales de infancia y adolescencia. Momentos de desarrollo moral y cognitivo, de trascendencia en la formación de nuestra personalidad y cerebro. No todas las personas consideran los mismos mitos (tomaremos ejemplos de la cultura popular) e incluso suponen una barrera intergeneracional, salvo casos que expondremos. También se mostrará como la relación con el mundo adulto y modelos sociales suponen una mitología personal para el adolescente, que percibe su vida como una "fábula personal", según la teoría del psicólogo David Elkind. Finalizamos con un ejemplo práctico de taller en un colegio de primaria.

Palabras clave: Mito, adolescencia, arquetipo, modelo, cultura pop, Elkind, Campbell.

Abstract: In this article, the mythical time perception is defined as reference to the personal myths of childhood and adolescence. Moments of moral and cognitive development, of transcendence in the formation of our personality and brain. Not all people consider the same myths (we will show examples of popular culture) and even suppose an intergenerational barrier, except for cases that we will expose. It will also show how the relationship with the adult world and social models suppose a personal mythology for the adolescent, who perceives his life as a "personal fable", according to the theory of psychologist David Elkind.
\end{abstract}

Keywords: Myth, adolescence, archetype, model, pop culture, Elkind, Campbell.

${ }^{1}$ UNED, Universidad Nacional de Educación a Distancia, Espanha. 


\section{El mito. Percepción del tiempo y verdad}

Siempre es necesaria una primera aproximación al mito. Quizá porque su definición es tan amplia como la cantidad de ámbitos y posibilidades de acción del mismo. Mito como fábula, como ficción alegórica, en la que fue primera entrada en el Diccionario de la Real Academia de la Lengua en 1884. G. S. Kirk evitó definiciones, incluso se opuso a ellas de forma abierta, ya que no hay ninguna que pueda ajustarse completamente a ninguna mitología si la aplicamos de forma global. Ni siquiera encuentra una categoría analítica de eficacia incuestionable (Kirk, 1997: 11). Sí podemos concluir, aunque siempre maticemos el contexto, que es símbolo, función social, el deseo de comprender ontológicamente el mundo y a nosotros mismos, aunque sea escenificado en narraciones casi oníricas. Expresión de nuestro miedo a la muerte, de sorpresa ante el cosmos y la vida. Como dijo Ernst Cassirer, el mito es parte de nuestra naturaleza psico-física (Cassirer, 1971: 64, 128).

El mito también remite al origen. Así ha sido, y si hoy no siempre conduce a un origen anclado en un momento pasado atemporal originario, un tiempo de acción perfecta ya que es momento creador y modelo, al menos nos habla de personajes y actitudes ejemplares; en este sentido, el mito tiene carácter axiológico. El tiempo de origen es ese tiempo mítico, esa "primera articulación" que, de forma cíclica, sucede siempre que se repite el ritual, se narra la historia, permaneciendo viva en nuestra memoria. Hoy, el mito es tanto un héroe religioso como un personaje de la literatura, el cine o el cómic. Un deportista, un magnate de los negocios. En mi personal aportación al campo del mito, propongo como primera articulación del tiempo mítico la norma atemporal de una determinada cultura, moral, religión o legislación. Entiendo, así, que la mitología como mónada originaria de sentido, axioma religioso o normativo responde a esta primera articulación. Jesús, Lenin o el cowboy remiten a un origen no cuestionable. No de modo lógico, pero incontestablemente inamovible desde el punto de vista emocional. Si pensamos en el cowboy, qué sería de los Estados Unidos si su héroe mitológico debiera describirse como un pendenciero y alcohólico racista que encierra en las reservas al legítimo nativo americano.

El mito es emoción, pasión, insistía Kirk. Una realidad hiperbólica, toda ella símbolo. El mito tiene una función poética que refuerza su función pedagógica y ontológica. El logos, lo vemos a diario, no lo puede todo y recurrimos al mytho como posible medio de expresión de miedos, pasiones o necesidades, una vía de escape y de 
búsquedas. Pero, y esto es importante, no olvidemos una tercera pata para este taburete que, al menos en mi opinión, es la sombra junguiana de las anteriores: la hybris. La desmesura, la pasión irracional, el instinto desatado. En la cuestión adolescente aludida en el título de este artículo, tiene especial relevancia; sea, sin más, una cuestión de adecuar las experiencias vitales y las hormonas en su debido emplazamiento.

Pero el mito no es verdad en el sentido en que pretende serlo el dogma religioso. No es esa clase de imposición de la fe. Es probable, así lo considera Paul Veyne, que los griegos fuesen conscientes de que los poetas mentían (Veyne, 2014: 13-15). Ni la historia ni la mitología se entendían como la entendemos hoy; el mito, de hecho, era falsa autoridad, simplemente la propuesta del poeta o dramaturgo. Heráclito, el pseudoHeráclito, destacaba el uso de lo alegórico, "la figura (trópos) que dice una cosa, pero significa otra distinta de la que menciona”. Para este Heráclito, Homero era un impío. Veyne nos habla de los mundos de verdad, y el mito no es más verdadero que la verdad ciudadana de la polis. Mito y política no dejan de ser dos facetas, dos dimensiones entre las muchas que, a modo de bricoleur, conforman nuestra vida, así, el pensamiento es una miscelánea de arte y creencia, narraciones y metáforas. Por tanto, el mito no es ni falso ni verdadero, y depende de quién y cómo nos lo transmita, por lo que cada mito podía aportar una idea diferente según el narrador, el receptor o la personalidad de una ciudad en particular. Incluso, no me parece descabellado el comentario, el mito, en la tragedia ática, depende de la recepción que el público depara a la obra. El dramaturgo ofrece un producto que contente a la masa, que le permita ganar el certamen que lo encumbre. El mito es una verdad re-construida. El mito se re-creaba en la recepción que de la obra tenía el crítico, el público y os poderes que dictaminan un premio al autor. ¿Es tan diferente de lo que sucede hoy en día? ¿No es el anfiteatro griego un cine al aire libre? Obviemos esta última y retórica pregunta si es menester.

La cuestión es que sí, creían en sus mitos, dice Veyne, siempre que entendamos que la verdad no es siempre la misma verdad según la persona y la circunstancia social. Sí, es cierto, tenemos esa curiosa y peligrosa capacidad de querer creer, así como siempre hay alguien interesado, como decía Mario Vegetti, en "parecer creer para hacer creer". Quizá por el bien común, ya que una sociedad con una estricta conducta moral y comportamiento basada en la divinidad ejemplar puede mantenerse estable, una cualidad homeostática que ofrezca seguridad y amparo al ciudadano. También supone, este hacer creer, una "teoría del terror", un fallo cognitivo, irracional, ya que nuestra mente no parece aceptar el futuro como carencia de pensamiento, por lo 
que nuestros ancestros han generado la ilusión de una mente inmortal (Bering, 2012: 132, $133,182)$.

Si ahora intentamos proponer una segunda articulación del tiempo mítico, nos encontramos con creencias o mitos que evolucionan a lo largo del tiempo junto a los cambios de su sociedad; insisto, es una propuesta personal, fruto de la investigación y la necesidad de diferenciar importantes diferencias entre mitos. En un principio estas narraciones o creencias remitían al mito de origen, pero los matices cambian en cuanto a la función social, a la propuesta arquetípica de un determinado personaje, a la valoración ética o axiológica de una acción particular. Así, considero esta segunda articulación como la propuesta mítica propia de un determinado momento y contexto histórico, social y cultural. Prometeo fue, finalmente, liberado de su castigo, gracias al perdón de Zeus, que permitió partir las cadenas a su hijo Heracles. Quizá era una imagen demasiado tiránica para el dios padre, y un lavado de cara nunca viene mal a quien ostenta el poder; la tragedia ática se dedicó a adecuar figuras divinas y heroicas, no solo cuestión política, me arriesgo a pensar que también estética y de sinergias de interacción entre creador, ciudadanía y gobierno. Nos advertía Leszek Kolakowski del peligro del mito totalizador que degenera en dogma, pero no suelen permanecer si no es en caso de desembocar en religión (Kolakowski, 2006: 33, 40). Mientras, nos decía Mircea Eliade, las mitologías pueden diversificarse según los contextos. Por ejemplo, en la Edad Media, los diferentes colectivos pueden atribuirse una mitología como hicieron los distintos oficios, la caballería o el clero.

Esta segunda articulación bien puede relacionarse con la "cuenca semántica" que Gilbert Durand definió en su mitodología (Durand, 2003). El sentido de la mitología cambia al mismo tiempo que cambia la sociedad, y Durand fue consciente de que los cambios producidos durante la revolución industrial fueron drásticos. Se universaliza a Freud y a Darwin, a la máquina como símbolo progreso, a la televisión como creadora de nuevos mitos. La cuenca semántica que identifica para nuestra época Durand abarca desde mediados del XIX hasta nuestros días. Está formada por diferentes "torrentes", es decir, corrientes dentro de un medio cultural que se originan a partir de hechos científicos, sociales, etc. En esta tesitura, determinados personajes dan nombre a una cuenca semántica, desde Alejandro Magno a Napoleón, como indica el propio Durand. En resumen, quizá sea suficiente aceptar que los mitos y el sentido de la vida cambian y que, en cada momento, ese sentido es expresado por narraciones y personajes diferentes. Es curioso, pero en la cultura popular, en los cómics, se ha entendido 
perfectamente esta idea. En los cómics Planetary y, posteriormente, The Authority, del guionista Warren Ellis, aparecen personajes considerados los “bebés del siglo". Estos son la representación o personificación del espíritu de cada siglo a lo largo la historia. Uno de ellos es la atípica heroína Jenny Quantum, que muere en el siglo XX para renacer en el XXI, siendo acogida por dos superhéroes homosexuales, Midnighter y Apollo. Héroe lunar y solar respectivamente, parodias sarcásticas, expeditivas y violentas de Batman y Superman. Los tiempos cambian y exigen nuevos mitemas, semas, morfemas y descripciones estéticas y axiológicas.

\section{Tercera articulación del tiempo mítico}

El ritual nos acerca a lo sagrado en su concepto religioso, como nos decía Eliade, además de recibir su efecto terapéutico y su carácter ejemplar (Eliade, 1991). Es ese momento fuera del tiempo, que sucede siempre y siempre está sucediendo; con valor axiológico y carácter apodíctico, por si no fuese suficiente. Es la moralina, el hecho sagrado, la verdad que nos acompaña siempre. No es conocimiento intelectual elaborado y aceptado, es experiencia vital, emocional, que a menudo implica una falta de crítica hacia este conocimiento, o bien una lógica de causa y efecto que, a pesar de actuar como la magia, se parece en cierta medida a la ciencia, como explicaba Cassirer (Cassirer, 2013). Nuestro conocimiento, nuestra experiencia de la vida se aprehende de un modo similar, a partir de un aprendizaje por imitación de modelos adultos, y por las narraciones o cuentos que, a modo de mito, nos muestran lo que es el mundo, la sociedad, las personas, nosotros mismos. No son argumentos lógicos, sino conductas moldeadas a partir de la experiencia, un ensayo y error emocional mientras esperamos que se reconozca nuestra individualidad dentro de un grupo de iguales. Esta experiencia es de crucial importancia, nos define, queda grabada a fuego; valor axiológico y carácter apodíctico, podríamos reiterar. La infancia es nuestro tiempo de origen, la adolescencia la etapa donde la aventura mítica cobra valor y forma, donde es analizada desde la lógica de un sentido a menudo teleológico.

Freud nos decía que el yo se modifica para crear el superyó cuando el primero no se ve satisfecho (sexualmente) a partir de la identificación primaria con las figuras paternales. Se identifica con ellas, las toma como modelos, pero amándose a sí mismo. Este ideal del propio yo trata de satisfacer las más elevadas búsquedas del hombre, su ser social y moral, religioso, suplantando la primera figura modelo, el padre o madre. Pero 
no solo con los padres, sino que establecemos lazos libidinales con la masa, que anula su conciencia en favor de un líder, sea religioso, político o un famoso pianista. Comprendemos el yo de otros en un proceso de identificación, que denominó proyección simpática, la cual nos ayuda a encontrar nuestro lugar en la sociedad y forjar nuestra personalidad. Albert Bandura desarrollo su teoría de modelaje en una estructura similar, donde la búsqueda de modelos por parte del niño es una búsqueda de sentido del mundo, de sus reglas y moral, un patrón que nos permita existir disfrutando de un mínimo bienestar. Bandura puntualiza que esto se da de forma universal, desde aquella persona ya adulta con autoestima baja que depende del modelo, como aquella otra confiada y ufana que convierte a su modelo en modelo idealizado, de prestigio. Se trata de un reforzamiento vicario, siendo recompensados emocionalmente cuando nuestro héroe triunfa, y sintiéndonos afligidos cuando nuestro modelo fracasa.

John Bowlby desarrolló la teoría del apego en los años 50 del siglo pasado. El apego por los padres aumenta las posibilidades de supervivencia en los primates; incluimos en esta categoría al ser humano. Un apego malogrado puede generar problemas de identidad y trastornos de personalidad. Los niños precisan de un adulto que sea ejemplo, además de llegar a comprender, gracias a esta figura, qué supone convertirse en uno. Por tanto, el modelo adulto es búsqueda de un referente, a modo de figura arquetípica que quedará fijada en la mente del niño. Entre el año y medio y los diecisiete se da el crecimiento cortical intelectual, tiempo en que la presión grupal, los medios audiovisuales o un reality show pueden llegar a provocar depresión, ansiedad o daños de cualquier otro tipo. Es nuestro mito particular, para lo bueno y para lo malo. Nuestras dudas, en este periodo, se muestran como una máscara de arrogancia, narrando nuestras anécdotas vitales como auténticas hazañas. Como el tiempo mítico que se repite, es menester permitir que verbalicen sus sueños y esperanzas, que no pierdan de vista su origen mientras sanean su memoria al actualizarla de forma constante en contacto con el presente. Es la edad de narraciones fantásticas, hiperbólicas y emocionantes. Edad de mitos, a los que la memoria recurrirá en el futuro. Bandura señala que en este aprendizaje social las narraciones tienen mayor impacto si representan de forma reiterada un hecho de forma física, en movimiento, de ahí la importancia de las narraciones de acción o ciencia ficción, sea cine, novela o cómic. Esta imagen plena de movimiento estimula la búsqueda de sentido como motor de arranque de dicha acción, existe una finalidad, es teleológico. Los niños generan mito; decía Piaget que esperan reacciones de objetos inanimados como respuesta a un acto moralmente reprobable o elogiable de una persona. 
Que un puente se derrumbe al paso de un malvado, sin ir más lejos. Y esto forma parte de la teoría de la mente. Nuestra mente simbólica, casi onírica, en busca de sentido, causaefecto que aúna aventura física y consecuencia moral. Pensamiento mítico, o mágico; en cualquier caso, no el pensamiento que asociamos con logos.

Propongo una tercera articulación del tiempo mítico como la mitología que conforma nuestra moral, personalidad o carácter durante nuestra infancia y adolescencia; narración, ficción, personajes históricos, sociales y, por supuesto, familiares y maestros. Es nuestro origen, y debe tener pleno sentido y temple. Es nuestro mito. Así, mi mitología va a diferir del resto de otras personas que me rodean; en este caso me refiero a la cultura popular, tema que estamos tratando. Incluso difiere de personas de mi misma generación; sea por cuestión de gustos, influencia familiar o del entorno, geografía, modas o mero azar. Me acompañará siempre, definiendo mi manera de ver el mundo. Nada, nunca jamás, llegará a provocar ese tipo de sentimientos como descubrimiento del mundo, de valores, de emociones ligadas a ideas o elecciones morales; épica de la inocencia de la infancia, el mundo a nuestros pies, el mundo en combate contra nosotros en la adolescencia. Pero, es lo más habitual, supone un salto intergeneracional de gran importancia.

\section{El mito intergeneracional: de Star Wars a Ready Player One}

Algunos filmes o, mejor aún, sagas, se convierten en puente intergeneracional. Varias generaciones han disfrutado de Star Wars desde los años 70; a estas alturas, Star Wars ya no es algo "moderno", ni siquiera "posmoderno" (entiéndalo a su gusto y mito personal). George Lucas consideró que toda una generación de niños y jóvenes estaba creciendo sin una mitología que le ayudase a definir o "vivenciar" los grandes valores, de ahí que se basase en el famoso monomito, en el camino del héroe, de Joseph Campbell. Sin duda alguna, elemento desglosado hasta el hastío en la obra de Lucas en numerosos artículos y publicaciones de todo tipo. Mas, ¿qué consiguió Lucas, casi sin darse cuenta?: Ofrecer el patrón del inconsciente colectivo junguiano más elaborado y obvio (y, por obvio y masivo, pop) de la historia del cine épico. El camino del héroe en un cuento fabuloso que comienza con aquella leyenda: hace mucho tiempo, en una galaxia mиy, mиy lejana... El cuento tradicional de caballeros andantes y princesas sumado al camino del héroe transportaba a varias generaciones al espacio, no solo a niños y adolescentes. Es más, la historia del joven Luke, que resulta no ser huérfano 
sin apellido, sino hijo del terrible Vader, quien domina la galaxia. Un monje guerrero con habilidades místicas le ofrece una espada y un destino, además de conocer a su hermana, Leia Organa, mujer de armas tomar. El mito del Arturo galáctico y su búsqueda del grial/fuerza Jedi está servido.

Star Wars mantuvo su empuje durante los 80 con las secuelas, especiales de televisión, cartoons y cómics. Mientras, el posmodernismo, signo de crisis, niega espacios conceptuales anteriores sin una propuesta definida para el presente. Decía Lyotard que vivimos en una pluralidad de reglas que son muestra de los muchos contextos que nos rodean; todo depende de circunstancias particulares. El mito en sí mismo, su naturaleza, no ha perdido fuerza, pero se ha transformado, y quizá el camino del caballero andante no pasó por su mejor momento en los 90. Años de una generación que alguien denominó X; años donde el cine o el cómic se oscurecieron, donde el rock se transformó en el grito desesperado del grunge. El mito Cobain se suicida, lejos de las muertes malditas, a la francesa, de otras estrellas del rock. Estamos en una época, como decía Alasdair MacIntyre, postvirtuosa. En la era del consumo incluso los mitos son producto, venta. El propio mensaje tiene su precio. Se crean mitos ad hoc, se ofrece consolación, emociones vicarias, lo que necesitamos escuchar, lo que reconocemos. La segunda de las trilogías es una apuesta comercial muy precisa, situando los hechos cronológicamente en un pasado inmediatamente anterior a la primera, por lo que vemos a algunos de los personajes de sobra conocidos en su juventud. La anterior, o primera, generación no puede evitar acudir a las salas de cine. Además, uno de los protagonistas es un niño que se transforma en adolescente, romance incluido, por lo que una nueva generación se acerca al mito, aunque, y esto es importante, será esta trilogía y no la primera su mito particular. A finales de los 90, y tras las incursiones americanas en Irak, la saga se vuelve muy política, incluyendo en la trama, como elementos fundamentales, la república, la democracia o el libre comercio. Conceptos políticos entendidos como mito en la nación norteamericana, hogar de la saga Star Wars. La guerra de Irak tiene su aquel, y no es cuestión menor: las mujeres entraron en primera línea de batalla como soldados.

La tercera trilogía es un nuevo cambio, en el que, aparentemente, se repite el patrón del monomito de la figura de Luke Skywalker en Rey, una joven que "despierta a la fuerza". Tras la segunda entrega, comprendemos que no es así, la similitud formal de la trama esconde una deconstrucción del camino del héroe que transforma el mensaje. Rey no es hija de ninguna estirpe aristocrática ni es anunciada por profecía alguna, ni tiene maestros o guías ni pretende convertirse en una guerrera de fama interplanetaria 
(típicas características heroicas); es una superviviente, no una heroína definida por el destino o el linaje. Finalmente, en The Rise of Skywalker, se produce un curioso y no siempre valorado hecho: Rey es hija de Palpatine, el emperador, el mal encarnado. Rey no es una Skywalker por linaje, sino por elección, y su valor reside en enfrentarse a su naturaleza maligna. Un nuevo arquetipo, el que parte del mal para acercarse al bien; no un ángel caído, sino la semilla de mal que escoge el camino de la luz. Hay más casos en estas últimas décadas, por supuesto. Desde el diablo Hellboy al medio vampiro Blade, o el salvaje Wolverine de los cómics. En estos tiempos, un arquetipo más que interesante.

La segunda entrega de esta última saga, The Last Jedi, es además un filme dominado por la presencia femenina, en un complejo muestrario de masculinidades y sororidad que merece su propio estudio. Por si no fuera suficiente, entre ambas películas aparece Rogue One, película donde los propios rebeldes asesinan por la espalda o actúan como terroristas. La moral se presenta difusa, abierta a la perspectiva personal, al matiz y a la duda. Y a la muerte, pues los protagonistas no reciben medallas como en Return of the Jedi en 1983 ni un futuro que disfrutar. Son tres trilogías muy diferentes, que quizá lo que tienen indiscutiblemente en común es ser un producto comercial impecable. Generaciones que defienden su trilogía a capa y espada láser, pero consumen todo el material de la extensa saga. Star Wars se ha convertido en mito intergeneracional, permite el debate, el intercambio de ideas, de interés en épocas donde el valor del mito es diferente, al igual que los efectos especiales o el aspecto físico de los actores y actrices escogidos. Generar un intercambio entre generaciones de consumidores de la saga es interesante considerando su contexto, momento histórico, respuesta emocional, valores aprendidos.

En estos momentos esperamos la cuarta entrega de Stranger Things, en un presente donde las series dominan el tiempo que dedicamos a la narración audiovisual. De nuevo, un puente bidireccional que aprovecha la nostalgia por los fructíferos años 80 en cuestión de personajes y películas de aventuras, a menudo familiares (estrategia legítima para llegar a un mayor número de público). Quizá sufrimos la carencia de ideas nuevas, o tenemos un vacío que llenar en cuanto a qué queremos transmitir. Stranger Things se alimenta del mito de la década de los 80, de películas donde unos críos en bicicleta salvan su pueblo, es decir, su propio universo. Sea Elliot en E.T. o Mikey en The Goonies. Para las nuevas generaciones, los nuevos actores infantiles/juveniles de moda. Para la generación de los 80, referencias de todo tipo, desde personajes, arquetipos, tramas, música e incluso Winona Ryder. La serie es otro puente intergeneracional tendido 
a través del medio de moda: las series de televisión. Como posible crítica, si analizamos esta narración como mito, es que no hay mito. Sí en el sentido de ciertos patrones heroicos, pero se da en cualquier otra narración, al igual que cierto tipo de arquetipos de héroe o antihéroe, o algunos más junguianos como la madre, el guerrero o, especialmente, el niño divino, cuyas características se aprecian claramente en un par de personajes: Eleven y Will. Niños puros, inocentes, sensibles a la llamada de la aventura o lo divino. Niños andróginos; ella con el pelo corto, con aspecto de chico en la primera temporada y él pálido, delicado, sensible, con el pelo largo y lacio (entendemos estas características como tradicionalmente femeninas). Al igual que en las películas citadas, E.T. y The Goonies, el puente intergeneracional también se da en la trama, ya que los niños se enfrentan solos a una determinada circunstancia o problema para, posteriormente, involucrar a los adolescentes y, en último término, a los adultos. Pero, al caso, no hay un elemento de transmisión de valores adecuado de forma específica a estos tiempos. Valores universales sí, atemporales, pero escondidos, como está siendo habitual, en el exceso de acción, efectos especiales o tramas imposibles con un número ingente de personajes. El mito nunca puede ser un simple divertimento.

Otros intentos se adecúan más a una época determinada, incluso como producto que cobra forma por condensación de ideas artísticas previas y el contexto social y científico; posmodernidad intertextual. Matrix es el combate contra el dominio de la máquina, el temor al mito de Prometeo, a la realidad virtual, al sistema como metáfora. Más allá de la pobre lectura que se ha hecho de la trilogía (no de la primera parte), denostada en sus segunda y tercera entregas, Matrix advierte, es Prometeica. Matrix identifica esta nueva era con la realidad virtual, cuerpo y mente cada vez más imbricados en lo maquinal, en la IA. Esta saga, también es cierto, no pretende establecer líneas de diálogo intergeneracional y, aunque ha pasado a la historia del cine, no parece resultar atractiva a las nuevas generaciones, acostumbradas a la serie o estreno de moda, o a las jóvenes estrellas. Otras historias tratan de acercarse o bien directamente al público adolescente, o bien servir de puente intergeneracional, mientras se publicitan como la última gran obra de la ciencia ficción. Es el curioso caso de Ernst Cline y su Ready Player One (RPO), novela del 2011.

En la novela, vemos como este siglo se convierte, en las próximas dos o tres décadas, en un lugar masificado y sucio, arrabal de caravanas amontonadas, gente sin trabajo, salud o realización personal. La salida a la que todos recurren, sea cual sea su edad, género o situación, es un juego virtual llamado Oasis. Una experiencia voluntaria, 
al contrario que en Matrix, donde un traje ayuda a simular las experiencias vividas en el juego. Podríamos hablar de la creación de una identidad virtual, algo que podría ser elemento digno de crítica en la película, pero que se acepta con normalidad e incluso con cierta alegría, a pesar de que supone una interacción descentrada de la sociedad. Personalidades y cuerpos virtuales diseñados, relaciones artificiales, búsquedas y objetivos alejados de cualquier realidad. Matrix es un mito apocalíptico, RPO es un mito integrado si seguimos la categorización de Umberto Eco. La identidad digital actual, programada por un sistema capitalista, ensalza la belleza del artificio. Ya no somos el simulacro de Baudrillard; somos, nosotros mismos, el mapa. RPO es la memoria juguetona de un escritor que revive en una novela de carácter juvenil sus mitos de adolescencia ya que, en el juego llamado Oasis (una suerte de paraíso en el desierto), nos enfrentamos y disfrutamos de toda la cultura pop de los 70, 80 y 90: el DeLorean, la moto de Kaneda en Akira, la música de Bowie o Van Halen, Space Invaders, Atari o Parque Jurásico. Steven Spielberg reconoce el filón, y plantea una película autorreferencial, viviendo su mito, que es el nuestro. Una película con una calidad visual inigualable, divertida... y que pretende establecer esa línea de diálogo entre generaciones. Pero en este caso no lo consigue, no es el éxito de taquilla y merchandising al que nos tienen acostumbrados. Han planteado una narración con los elementos adecuados a la adolescencia de hoy: realidad virtual, identidades digitales como opción personal de crecimiento, encontrar el amor en la red, enfrentamiento al mundo adulto y encuentro con héroes y adultos modelo. Sin embargo, el medio es un sinfín de referencias del pasado, la mayor parte de ellas desconocidas al adolescente de hoy. No son los mismos mitos, con todo lo que eso implica. Porque aprendimos algo, algo de peso con Bowie, Akira o Parque Jurásico, enseñanzas adecuadas a una época; mitos. No se pueden convertir en elementos formales vacíos de significado en épocas descontextualizadas. Son estériles, tan solo la cáscara del huevo de pascua (easter egg) escondido en el juego de Oasis.

\section{Audiencia imaginaria y la fábula adolescente}

Llegados a este punto, desearía considerar lo que hoy podríamos entender por narración adolescente. Sí, siempre ha existido material para jóvenes, al igual que ha existido el cuento infantil. Pero debemos recordar que la adolescencia es una etapa definida como tal solo en tiempos modernos. Desde luego encontramos diferencias, y no son tan sutiles como puedan parecer. Hace unas décadas, muchos de los héroes o heroínas 
para jóvenes eran adultos o jóvenes que deseaban dejar atrás la adolescencia. Su búsqueda personal, la aventura, los llevaba a abandonar esta etapa de la vida para madurar y alcanzar el mundo adulto. Nadie quería ser adolescente, queríamos ser "mayores". La problemática de la aventura era adulta, sus comportamientos y decisiones, también. Quizá como ensalzamiento o reconocimiento de lo adolescente, quizá como estrategia comercial, las narraciones han cambiado, definiendo personajes como adolescentes conscientes y orgullosos, con los problemas y concesiones habituales. Exigen el derecho a ser adolescente. La adolescencia se convierte así en el hipotexto, que diría Gérard Genette, el marco referencial sobre el que se construye el resto de la historia.

La adolescencia es el momento, periodo, en que crece y se desarrolla el lóbulo frontal, el de las emociones y la conciencia social. Los modelos, como ya hemos visto, son necesarios; por eso es necesario mentar a Freud, Bandura o Bowlby. Una verdadera pena, una ocasión perdida cuando la narración se centra en acciones rebeldes sin causa, amoríos, belleza o ciertos alardes de frivolidad. Sin embargo, muchas de estas obras, y de manera especialmente destacable, reflejan la relación (tan mítica) con el padre o madre; el amor en todas sus manifestaciones u otras emociones como el miedo o la ira; la responsabilidad como elemento conductual fundamental, la conciencia del acto propio y ajeno. Que estudie, personalmente, la ciencia ficción o el género de aventuras responde al hecho del acto físico descrito en la narración que, como ya hemos visto, posibilita la integración emocional e intelectual del mensaje de una manera más fuerte. Como el mito. Y, como el mito, estos géneros establecen la estructura o base en su trama que Campbell definió como monomito, o crean una batería más que considerable de arquetipos o estereotipos que todos reconocemos (tal y como definió Jung). Toda historia ya ha sido contada de alguna forma, solo hay que adaptarla a las necesidades de los nuevos tiempos. Y si repito esto, es porque encaja demasiado bien como para ser ignorado en la teoría del psicólogo americano David Elkind.

Elkind trabaja sin olvidar los estadios madurativos del cerebro, la sinaptogénesis, o las etapas del desarrollo ya planteadas por Piaget, es decir, el ritmo adecuado entre la madurez neuronal, la madurez física del órgano llamado cerebro y los aprendizajes adecuados a la edad de la persona. El niño construye su realidad a través de un proceso de aproximación a la vida adulta, tomando como modelos a los adultos que lo rodean mientras trata de vivir su propia vida, experimentando su propia historia (que Jung o Campbell han entendido como el mito personal). Los descubrimientos intelectuales, morales o emocionales se integran a través del juego simbólico. Esto supone un reto 
doble. Por una parte, ponerse a sí mismo a prueba para estar a la altura del adulto, por otra retar al adulto a estar a la altura del modelo ideal, mítico. Elkind pone un ejemplo muy claro, Superman. Personajes como este relativizan las capacidades de los padres, nos enseña que no son todopoderosos. El juego simbólico, o estos modelos simbólicos, como son los personajes "míticos", ayudan a reconfigurar el sentido de memorias pasadas y la visión que tienen del mundo y las personas que los rodean (Elkind, 2001: 109, 110, 119, $122,123)$.

Así, llegamos al concepto de "audiencia imaginaria”. En la vorágine vital adolescente, en el intercambio de experiencias entre el mundo y su ser interior, el adolescente confunde lo que piensa de sí mismo con lo que los demás piensan de él. La sensación puede ser rememorada, somos el centro de atención, nos sentimos observados. Es probable que se sientan culpables de lo que sucede alrededor. Elkind cita el típico caso del divorcio de los padres. El adolescente no sólo se siente culpable, sino que llega a creer que la audiencia de su entorno está atenta a todo tipo de causas y detalles. Y es ahora, en este momento, cuando el adolescente genera su "fábula personal": si todos le observan, él debe de ser especial. El matiz mítico aquí es sutil, pero innegable. El adolescente, de manera totalmente irracional, puede generar sensaciones peligrosas como sentirse intocable. El destino jamás le deparará un accidente, determinadas enfermedades o un embarazo no deseado, lo que implica no medir riesgos y exponerse a situaciones en ocasiones realmente peligrosas. Caigo en la tentación de recordar a Campbell cuando decía que todos vivimos un mito, una vida heroica, un tanto desmedida en la primera juventud. El arquetipo de Jung parece dirigirse a una imagen del instinto hacia la cual se dirige nuestra naturaleza. El joven, a menudo, en este sentirse especial, se siente víctima de las sincronicidades (¿la llamada a la aventura?) que el mismo Jung definió, y que hoy vende tantos libros de autoayuda: el universo conspira en mi contra o a mi favor. La intuición, afirma Jung, nos ayudará a dar sentido a estas "sincronicidades", a tomar la elección correcta.

Por citar un ejemplo de la cultura pop, de la MTV británica, veamos qué sucede en la serie adolescente Misfits, emitida entre 2009 y 2013. Jóvenes marginales, con problemas de conducta, escolares o familiares que, en una tormenta eléctrica, adquieren poderes: dar marcha atrás en el tiempo para evitar los errores imperdonables de la noche anterior; volverse invisible cuando nadie te mira para evitar problemas; que te adoren y amen hasta la violencia si rozan tu piel; escuchar en tu mente las emociones de otros; y, a aquel que se expone a riesgos continuos, se le concede la inmortalidad. 
Capacidades adecuadas a cada uno de los personajes, a sus personalidades y circunstancias, en un ritmo frenético que no permite la digestión pausada y racional de la trama, mientras los cuidadores del centro de menores donde sucede la acción mueren y se suceden uno tras otro. Circunstancia adolescente. Producto adolescente en cuestión de intereses, emociones y ritmos; combustión espontánea, hybris, búsqueda constante. Producto intergeneracional cuando el adulto permite que el ethos y el pathos de la propuesta se aposente en el fondo de la taza, entonces reconozco el patrón, lo he vivido. Nuevo mito, pero mito sin referencias comunes; sin referencias, podríamos arriesgar. Es decir, dentro de los cómics de los X-men encontramos personajes como Fénix, con reciente película propia, siendo una referencia mítica evidente, aunque sea, simplemente, cuestión de forma y no de fondo. Sin embargo, pasan desapercibidas decenas de referencias, como estructuras narrativas literarias. Tomemos ejemplo del Calibán de Shakespeare en su obra La tempestad, personaje primitivo y esclavizado, materialista, frente a Ariel, personaje que idealiza el espíritu. Calibán, personaje que Rousseau empleó para hablarnos de este binomio material/espiritual. En los cómics, un mutante de los Morlocks vive apartado del mundo en las alcantarillas, dependiente del mando hegemónico de la mutante Calisto, un Calibán materialista, aficionado a recolectar objetos que guarda en su escondrijo. Calibán se enamora perdidamente del miembro de los X-men Kitty Pride, un ángel aún adolescente cuyo poder es volverse intangible, etérea, perder su materia. Kitty tuvo varios alias superheroicos: Gata Sombra, Espíritu... o Ariel. Guionistas como Chris Claremont han tejido narraciones intergeneracionales con referencias de la cultura pop, la política, literatura o mitología. Parte del éxito al reeditar hoy estas páginas, reside en la universalidad del mensaje, en el patrón inconsciente, por desgracia no en los conocimientos acerca de las referencias que esconden.

Volviendo a David Elkind, la fábula personal y la audiencia imaginaria nos acompañarán de por vida. Es cuestión, en ocasiones, de esperanza, un escudo contra el día a día. Un ejemplo de Elkind es el soldado que necesita creer que volverá vivo del frente. Es curioso, y no dejo de encontrar similitudes con el aspecto onírico, mágico e irreal del mito, que la adolescencia es, en ciertos aspectos, similar al delirio (Psicothema, 2012). En particular la fábula personal y la audiencia imaginaria. Son experiencias cuasi psicóticas. En otro tipo de cuestiones, es cierto que tratamos de adelantar de forma absurda, ineficaz e imposible la maduración hacia el mundo adulto en los niños, del mismo modo que tratamos de estirar la adolescencia hasta edades absurdas e igualmente ineficaces como búsqueda de una vida plena y sana. En lo físico, en lo intelectual. Nos 
resultaba insultante, hace un tiempo, que nos llamasen adolescentes cuando ya habíamos cumplido la veintena. Hoy, se dilata hasta lo insospechado en el ocio del que se disfruta, en el contenido de muchos de nuestros intereses o en las narraciones que nos venden, en cómo vemos nuestro cuerpo y nuestro proyecto de vida. Intereses comerciales; siempre es más sencillo vender algo a una mente acrítica, receptiva de forma heterónoma a lo que le ofrecen. El paradigma capitalista es adolescente, o nos invita a serlo. El mito, obliga.

\section{Apéndice: El otro día en Hawái}

Un día en Hawái Poseidón estaba en la playa mirando Instagram y encontró una foto de Thor y Ulises liados y se enfadó mucho.

Poseidón tiró el móvil al suelo; mientras tanto Thor y Ulises estaban dando un paseo y se encontraron el móvil tirado en la arena, vieron que Poseidón había visto la foto publicada por ellos, decidieron ir a buscar a Poseidón para explicarle lo que pasaba, por el camino se encontraron a Medusa sentada en un banco cabizbaja y le preguntaron por qué estaba siempre sola, triste, enfadada... y ella les explicó que antes era una mujer bella, sirviente de Atenea pero que un día Poseidón la encontró y quiso violarla, ella se negó y él la convirtió en una mujer con serpientes en la cabeza y cuando a ella le miran a los ojos se convierten en piedra.

Mientras conversan Thor, Ulises y Medusa llega Poseidón; escucha una parte del final que estaba contando Medusa y le dice que todo es mentira.

Thor le pide a Poseidón que cuente su versión. Y este cuenta:

"Un día cuando estaba durmiendo me desperté porque oí que habían abierto la puerta y cuando me giré vi a Medusa con una espada que tenía en su punta veneno de serpiente, rápidamente me levanté y decidí convertirla en lo que es ahora.”

Al ver que era muy tarde decidieron quedar el día siguiente para aclarar las cosas.

Pero no aparecieron ni Medusa ni Poseidón.

Thor al ver que no aparecía Medusa llamó a su amigo Ra para que hackearan el móvil de Poseidón y se encontraron una foto en la que aparecían Poseidón con Medusa atrapada en una jaula.

Mientras tanto Medusa intenta encontrar una forma de salir de la jaula y se acuerda de que puede convertir a la gente en piedra y entonces se quita las gafas y convierte en piedra a la mascota de Poseidón, un unicornio. 
Pasado un tiempo llegó Thor y sacó a Medusa de la jaula.

Poseidón al ver que se escapaban Thor y Medusa provocó un sunami y murieron todos.

Alumnado de $6^{\circ}$ C, C.E.I.P. Ponte dos Brozos; Arteixo, A Coruña. Talleres de creación literaria y género, marzo 2017.

La casualidad convirtió este taller, con esta clase en particular, en un muy buen ejemplo de cómo el mito es una herramienta pedagógica fabulosa. La propuesta era sencilla: escribamos todos juntos un cuento. No se advertía en ningún momento de los problemas que podía generar la elección de los personajes, que tenían tendencia a ser, normalmente, masculinos. Son los propios alumnos quienes proponen personajes mitológicos, encontrando una dificultad: apenas conocen diosas u otros personajes femeninos y no saben atribuirles una personalidad o cualidad. Sólo se les ocurre Medusa, como ejemplo de maldad. Al conocer su encuentro con Poseidón identifican violencia de género dentro del mito (me refiero, por supuesto, al encuentro que narra la mitología, en el que la Gorgona rechaza los intentos de abuso del dios). Identifican el hecho, al culpable y a la víctima, sorprendidos de que no se haya aclarado de la forma correcta en la narración clásica. Así, deciden reconvertir a los personajes masculinos escogidos. Es más, identificando con absoluta claridad las cualidades masculinas ya no de los mitos, sino de las narraciones que conocen, en general: Thor como la fuerza bruta, la violencia como recurso resolutivo de problemas; y en Ulises, la astucia e inteligencia. En esta reconversión del paradigma, los convierten en pareja. Por supuesto, debemos tener en cuenta que su conocimiento de mitos y leyendas, de aquellas de las que cine o literatura continúan proponiendo nuevas versiones, es decididamente occidental. Por otra parte, solo elementos de la propia cultura tienen un peso emocional considerable como para vivenciar con intensidad la narración.

Es patente la emocionalidad, la pasión con que viven el aspecto creativo de analizar y reconvertir, de escribir un mito. Comprenden el sentido, el valor de lo que quieren representar, con una seguridad e ímpetu que una sencilla explicación teórica no siempre es capaz de ofrecer. El acto creativo ha sido importante, el ritual. Se han expresado, han manifestado algo con validez ontológica y moral.

Además, han participado de lo que consideré primera articulación del tiempo mítico: han recurrido, motu proprio, a lo conocido por todos, a la mitología 
clásica, sabiendo de forma más o menos consciente que expresa conceptos, generalidades, estereotipos, ideas reconocibles, metáforas.

No pueden evitar la segunda articulación; es decir, no conocen al Thor mitológico, sino al de los cómics o las películas de la Marvel Comics, así como otros personajes que han aparecido en alguna película reciente: como ejemplo, Medusa y Poseidón en Ira de Titanes, del 2012 o la saga de Percy Jackson, del escritor Rick Riordan.

En cuanto a la tercera articulación hemos tenido que buscar un idioma común, tratando de dialogar para saber exactamente qué necesitan expresar y a través de qué personajes, por lo que explican su visión de Thor, Medusa o Ulises, mientras que yo propongo la mía. No sólo el conocimiento clásico y la experiencia contemporánea, sino cómo lo vivimos. Esto supone no lanzarnos a una visión proyectiva de futuro acerca de cómo esperamos que evolucione la sociedad y la moral, el trato entre todas las personas.

En cuanto a un análisis literario de trama y personajes, reconocer que la presencia de $\mathrm{Ra}$ obedece al alarde de algún alumno o alumna por demostrar conocimientos. (No alcanzo a comprender por qué Ra es un buen hacker.) El deseo de ensañarse con una especie protegida como es el unicornio es poco claro, pero valoro el riesgo literario que supone. Quizá algo freudiano, pero son aguas turbulentas y rehúyo el reto. En cuanto al sunami, me gustaría decir que una alumna especialmente brillante recurrió a la hybris desmedida del viril Poseidón. Pero no. Se nos agotaba el tiempo y había que finalizar la historia. Como nos sucede en este mismo instante.

\section{Referências}

BANDURA, Albert. Teoría del Aprendizaje Social. Madrid: Espasa-Calpe, 1982.

BAUDRILLARD, Jean. Cultura y simulacro. Barcelona: Kairós, 2008.

BERING, Jesse. El instinto de creer. La psicología de la fe, el destino y el significado de la vida. Barcelona: Paidós, 2012.

BETTELHEIM, Bruno. Psicoanálisis de los cuentos de hadas. Barcelona: Grijalbo Mondadori, 1994.

BOWLBY, John. La Separación afectiva. Barcelona: Paidós, 1985.

CAMPBELL, Joseph. El héroe de las mil caras. Psicoanálisis del mito. México, D.F.: Fondo de Cultura Económica, 2010. 
CAMPBELL, Joseph. El poder del mito. Barcelona: Emecé Editores, 1991.

CASSIRER, Ernst. La filosofía de las formas simbólicas I. El lenguaje. México D.F.: Fondo de Cultura Económica, 1971.

CASSIRER, Ernst. La filosofía de las formas simbólicas II. EI pensamiento mítico. México D.F.: Fondo de Cultura Económica, 2013.

DE ROMILLY, Jacqueline. ¿Por qué Grecia? Madrid: Editorial Debate, 1997.

DURAND, Gilbert. Mitos y sociedades. Introducción a la mitodología. Buenos Aires: Editorial Biblos, 2003.

DURAND, Gilbert. De la mitocrítica al mitoanálisis. Figuras míticas y aspectos de la obra. Barcelona: Editorial Anthropos, 1993.

ECO, Umberto. Apocalípticos e integrados. Barcelona: Debolsillo, 2010.

ECO, Umberto. El superhombre de masas. Barcelona: Penguin Random House, 2012. EGUÍA, Xan. Mitología Futura. De Neo a Prometeo: construyendo el nuevo mito. A Coruña: Editorial Bululú, 2017.

ELIADE, Mircea. Mito y realidad. Barcelona: Editorial Labor, 1991.

ELKIND, David. All Grown Up \& No Place to Go. Teenagers in Crisis. Reading, Massachusetts: Addison-Wesley Publishing Company, 1984.

ELKIND, David. The Hurried Child. Growing Up Too Fast Too Soon. Cambridge, Massachusetts: Perseus Publishing, 2001.

FREUD, Sigmund. El yo y el ello. Madrid: Alianza Editorial, 1988.

FREUD, Sigmund. Psicología de las masas y análisis del yo. Madrid: Biblioteca Nueva, 1924.

JUNG, Carl Gustav. Símbolos de transformación (Edición revisada y aumentada de Transformaciones y símbolos de la libido). Barcelona: Ediciones Paidós, 1990.

JUNG, Carl Gustav y KERÉNYI, Karl. Introducción a la esencia de la mitología. El mito del niño divino y los misterios eleusinos. Madrid: ediciones Siruela, 2004. 
KIRK, G. S. La mitología. Interpretaciones del pensamiento mítico. Montesinos, 1997.

KIRK, G. S. La naturaleza de los mitos griegos. Barcelona: Argos Vergara, 1984.

KOLAKOWSKI, Leszek. La presencia del mito. Buenos Aires: Amorrortu, 2006.

MORENO, Fernando Ángel. La ideología en Star Wars. Madrid: Guillermo Escolar Editor, 2017.

Psicothema 2012. Vol. 24, $\mathrm{n}^{\text {o }}$ 1, pp. 1-9 ISSN 0214 - 9915 CODEN PSOTEG www.psicothema.com Copyright (C) 2012 Psicothema

VEGETTI, Mario. El hombre y los dioses, en VV. AA. Jean Pierre Vernant (Ed.). El hombre griego. Madrid: Alianza Editorial, 1995.

VERNANT, Jean-Pierre y VIDAL-NAQUET, Pierre. Mito y tragedia en la Grecia antigua I. Madrid: Taurus, 1987.

VEYNE, Paul. Les Grecs ont-ils cru à leurs mythes? Lonrai: Éditions du Seuil, 2014.

Recebido em maio de 2020. Aprovado em setembro de 2020. 